\title{
Ata Hasanpur, Zahra Hashemi. "A comparative Study of the New sassanides Stuccos from Qela Gowri, Ramavand, Luristan, Iran"
}

\section{Rémy Boucharlat}

\section{OpenEdition}

Journals

Édition électronique

URL : http://journals.openedition.org/abstractairanica/47054

DOI : $10.4000 /$ abstractairanica.47054

ISBN : 1961-960X

ISSN : 1961-960X

Éditeur :

CNRS (UMR 7528 Mondes iraniens et indiens), Éditions de l'IFRI

\section{Référence électronique}

Rémy Boucharlat, «Ata Hasanpur, Zahra Hashemi. "A comparative Study of the New sassanides Stuccos from Qela Gowri, Ramavand, Luristan, Iran" », Abstracta Iranica [En ligne], Volume 37-38-39 | 2018, document 69, mis en ligne le 30 décembre 2018, consulté le 02 octobre 2020. URL : http:// journals.openedition.org/abstractairanica/47054 ; DOI : https://doi.org/10.4000/abstractairanica. 47054

Ce document a été généré automatiquement le 2 octobre 2020.

Tous droits réservés 


\title{
Ata Hasanpur, Zahra Hashemi. "A comparative Study of the New sassanides Stuccos from Qela Gowri, Ramavand, Luristan, Iran"
}

\author{
Rémy Boucharlat
}

\section{RÉFÉRENCE}

Ata Hasanpur, Zahra Hashemi. "A comparative Study of the New sassanides Stuccos from Qela Gowri, Ramavand, Luristan, Iran" in Rolf A. Stucky, Oskar Kaelin, Hans-Peter Mathys (eds.). Proceedings of the 9th International Congress on the Archaeology of the Ancient Near East, June 9-13, 2014, University of Basel, vol. 3 Reports. Wiesbaden: Harrassowitz, 2016, p. 417-428.

1 Dans le cadre des fouilles nécessitées par la construction d'un barrage sur la Seymareh, près de Kuhdasht au Lorestan, plusieurs monuments et sites de la période sassanide ont été repérés et certains d'entre eux ont été sondés. Ainsi à environ $400 \mathrm{~m}$ de la ville ancienne Barz Qavelah, une résidence a été fouillé en 2011 et 2012. Le bâtiment comprend principalement un portique de 8,75x 3,50 m, à trois supports, une colonne circulaire et deux demi-colonnes, qui ouvre sur une série de trois longues salles parallèles elles-mêmes suivie d'une espace long perpendiculaire. Cette construction a livré des centaines de fragments de décor en stuc, dont aucun n'était en place apparemment. On rencontre des représentations humaines, masculine et au moins une féminine, souvent limitées au buste ou à un bras, mais surtout beaucoup d'animaux, ours, cerfs et oiseaux divers. Les motifs géométriques et floraux sont très variés. D'autres stucs étaient plaqués sur des éléments d'architecture, ouvertures, arcades. Par comparaison avec des ensembles de la région de Téhéran, comme Chal Tarkhan, Rey ou Tepe Mil, Varamin, les fouilleurs proposent une date dans le dernier quart de l'époque 
sassanide, VIe et début VIIe s. Il n'est pas impossible que tout ou partie de ce décor soit déjà de l'époque islamique ou modifié à cette époque.

\section{AUTEURS}

\section{RÉMY BOUCHARLAT}

UMR 5133 CNRS-Université de Lyon 